\title{
Synchronization of an Antiferromagnetic Josephson-like Oscillator with an External AC Signal
}

\author{
D.V. Slobodianiuk*, O.V. Prokopenko
}

\author{
Taras Shevchenko National University of Kyiv, 64/13, Volodymyrska St., 01601 Kyiv, Ukraine
}

(Received 22 April 2020; revised manuscript received 15 October 2020; published online 25 October 2020)

\begin{abstract}
Magnetization dynamics in a highly nonlinear antiferromagnetic Josephson-like spintronic oscillator under the action of DC and AC signals is studied theoretically and numerically, and the regime of the oscillator synchronization to an external AC signal has been found and investigated. We revealed that the synchronization bandwidth of the oscillator substantially depends not only on the external force amplitude (which is typical), but also on the oscillator nonlinearity. This behavior arises from the highly nonlinear nature of the considered system. Our theoretical and numerical analyses show that the generation frequency of the oscillator depends on the applied electric DC current in a nonlinear way. Thus, the correct choice of the working point characterized by some particular value of the nonlinearity coefficient is important for the considered system to work properly, and it can be used for maximizing the oscillator synchronization bandwidth. Obtained results are important for the further development of antiferromagnetic terahertz-frequency spintronic oscillators and their applications. The developed formalism and numerical simulations can also be used for the description of strongly nonlinear non-isochronous oscillators of any nature.
\end{abstract}

Keywords: Antiferromagnet, Oscillator, Synchronization, Nonlinearity.

DOI: 10.21272/jnep.12(5).05013

PACS numbers: 75.50.Ee, 05.45.Xt

\section{INTRODUCTION}

One of the most promising areas of development in modern nanoelectronics is spintronics based on the utilization of mulilayer and single-layer nanoscale magnetic structures [1]. Such devices are usually implemented as spin-torque nano-oscillators based on magnetic multilayer nanostructures [2-3] or spin-Hall oscillators (SHOs) based on bilayer (magnetic/heavy metal) nanostructures $[4,5]$. They are biased by a DC current and produce an output AC signal; hence, they can be used as nanoscale AC signal sources [6,7]. However, the same spintronic nanostructures can be used as passive (no DC current is applied) or DC biased AC signal detectors [8-10] and energy harvesters [8], which are able to convert an input AC signal to an output DC voltage, as well as other signal processing devices.

Nowadays spintronic oscillators, detectors and other devices mainly utilize ferromagnets [1-11]. Such systems are well studied experimentally $[1-5,8,11]$ and theoretically or numerically $[3,6,7,9,10]$. However, these spintronic devices have at least one critical drawback: they can usually operate at frequencies less than $\sim 50 \mathrm{GHz}$. In contrast to this, antiferromagnets (AFMs) possessing a very strong internal magnetic field of the exchange origin have characteristic working frequencies of several hundreds of $\mathrm{GHz}$ and even several $\mathrm{THz}$ [1218]. Hence, antiferromagnetic materials can be useful for the development and creation of current-driven ultrafast nanoscale [12-15] and microscale $[16,17]$ devices operating in the frequency range of $0.1-10 \mathrm{THz}$.

It should be noted that despite the mentioned above significant advantages of antiferromagnetic oscillators over ferromagnetic ones, the behavior and properties of antiferromagnetic systems have not been thoroughly studied at the moment, while antiferromagnetic spintronics is considered as one of the most promising and emerging fields in modern spintronics [12]. In particular, the problems of synchronization of an AFM SHO with an external AC signal and/or other AFM SHOs has only been started recently $[12,18]$.

In this paper, we theoretically/numerically investigate the synchronization of an antiferromagnetic Josephson-like oscillator [13-15] (specific type of antiferromagnetic SHOs) with an external AC signal for a rather wide range of signal frequencies and powers. The developed numerical model predicts that the system synchronization bandwidth should substantially depend on the oscillator's nonlinear properties, and by selecting an appropriate oscillator working point a maximum value of the synchronization bandwidth could be obtained.

\section{THEORETICAL MODEL}

To describe the magnetic dynamics of an AFM oscillator under the action of an external signal we can use the following equation derived from the so-called sigma-model $[12-15,19]$ :

$$
\frac{1}{\omega_{e x}} \ddot{\varphi}+\alpha \dot{\varphi}+\frac{\omega_{e}}{2} \sin 2 \varphi-\left(\tau+\tau_{f} \cos \left(\omega_{f} t\right)\right)=0,
$$

where $\varphi$ is the Neel vector angle in an AFM, $\omega_{e x}$ is the exchange frequency, $\alpha$ is the Gilbert damping constant, $\omega_{e}=\gamma H_{e}, \gamma$ is the modulus of the gyromagnetic ratio, and $H_{e}$ is the easy plane anisotropy field. We consider a normalized electric current (in angular frequency units), which determines the oscillator behavior, as two simultaneously existing components: DC one $\tau$ and AC component with amplitude $\tau_{f}$ and angular frequency $\omega_{f}$.

The most important features of Eq. (1) are the following. Eq. (1) describes the dynamic of the Neel vector that rotates in the easy plane of the AFM. This is a

\footnotetext{
*denslobod@ukr.net
} 
simplified equation that can be obtained from the full Landau-Lifshitz system of equations for two sublattices' magnetization vectors. The threshold DC current value that is needed for the generation is $\tau_{t h}=\omega_{e} / 2$. When this current is reached, the Neel vector begins to rotate in the easy plane of the AFM with angular velocity $\dot{\varphi}$ and frequency $\omega_{g}=2 \tau / \alpha$. As we can see this frequency depends only on the applied DC current value and the Gilbert damping constant and does not depend on other system parameters. This is very important conclusion for possible practical applications of such systems. Finally, using the inverse spin-Hall effect, rotation of the Neel vector can be transformed into the varying electric field $E$ proportional to the Neel vector rotation speed: $E \square \dot{\varphi}$.

\section{NUMERICAL ANALYSIS AND DISCUSSION}

First of all, let us consider the dynamics of the AFM oscillator having parameters $\alpha=0.01, H_{e x}=9 \cdot 10^{6} \mathrm{Oe}$, $H_{e}=625 \mathrm{Oe}$, without an external AC signal $\left(\tau_{f}=0\right)$. Fig. 1 shows the dependence of the AFM oscillator frequency on the applied bias DC current. The curve shown by a black line is calculated from (1), while a red curve shows the approximate theoretical dependence $\omega_{g}=2 \tau / \alpha$.

As one can see, in the vicinity of the threshold point $\left(\tau / \omega_{e}=0.5\right)$ the AFM oscillator frequency is significantly deviated from the theoretical prediction $\omega_{g}=2 \tau / \alpha$. In contrast, at large DC current values the theoretical estimation for the oscillator frequency is rather precise. This behavior indicates that an AFM oscillator is fundamentally nonlinear in nature.

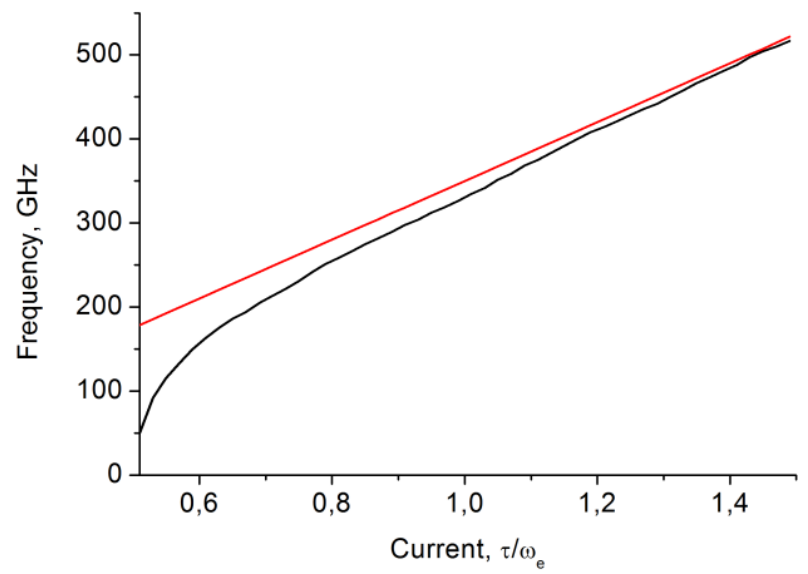

Fig. 1 - Dependence of the AFM oscillator frequency $\omega / 2 \pi$ on the normalized applied DC current $\tau / \omega_{e}$. The black curve is obtained from the simulations: the red line is a theoretical dependence. Parameters of the system: $\alpha=0.01, H_{e x}=9 \cdot 10^{6} \mathrm{Oe}$, $H_{e}=625 \mathrm{Oe}$

It should be noted that Gilbert damping parameter $\alpha$ plays an important role in the oscillator dynamics. For a relatively small damping parameter $\alpha_{2}=2 \cdot 10^{-3}$ an AFM oscillator becomes almost linear: generation frequency of such an oscillator coincides very well with the theoretical estimation $\omega_{g}=2 \tau / \alpha$. However, in our paper we will consider the case of large Gilbert damping parameters and, thus, the case of nonlinear AFM oscillator behavior.
Fig. 2 shows simulation results in the case when an additional AC current with two different frequencies, $\omega_{f}=2 \pi \cdot 150 \mathrm{GHz}$ and $\omega_{f}=2 \pi \cdot 400 \mathrm{GHz}$, is applied to the system. As one can see, the AFM oscillator synchronizes to an external AC signal. However, the synchronization bandwidths have substantially different values for different AC signal frequencies. Obviously, the bandwidth for the $150 \mathrm{GHz}$-signal is larger than the one for the $400 \mathrm{GHz}$-signal. This discrepancy is even more striking, when we recall that the external AC signal amplitude $\tau_{f}=0.15 \omega_{e}$ is the same for both considered cases.

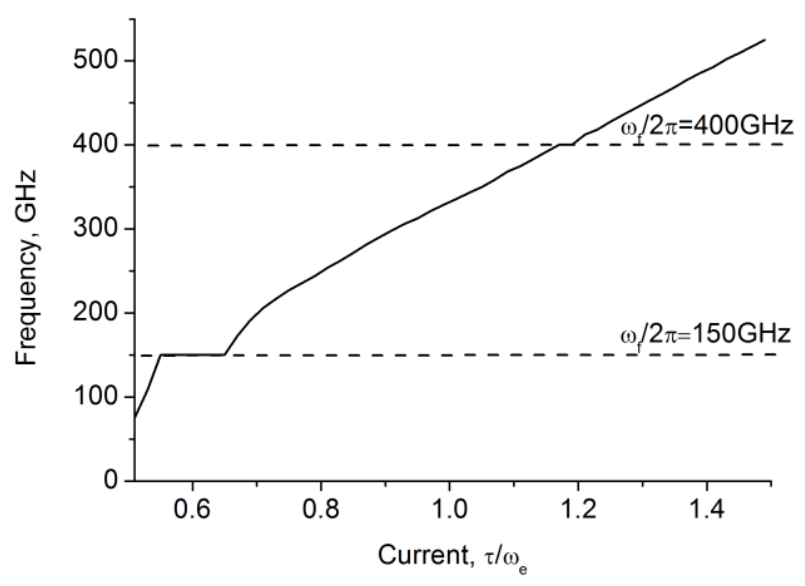

Fig. 2 - Dependence of the AFM oscillator frequency $\omega / 2 \pi$ on the normalized applied DC current $\tau / \omega_{e}$ for two different AC frequencies $\omega_{f}$. The black curve is calculated numerically, while the dashed lines are used as guides for an eye. Calculations are performed using the following system parameters: $\alpha=0.01, H_{e x}=9 \cdot 10^{6} \mathrm{Oe}, H_{e}=625 \mathrm{Oe}, \tau_{f} / \omega_{e}=0.15$

It is known from the synchronization theory [20] that the synchronization bandwidth of an oscillator is directly proportional to the synchronization force amplitude ( $\tau_{f}$ in our case). Thus, the result shown in Fig. 2 cannot be explained according to the linear theory [20]. Recalling that an AFM oscillator is a strongly nonlinear oscillator [13-15], one should use the specific nonlinear theory [6] for its description. One of the main results of the theory is the following: the synchronization bandwidth of a nonlinear oscillator depends not only on external force amplitude $F_{0}$ but also on the oscillator nonlinearity coefficient $N$ [6]

$$
\Delta=F_{0} \sqrt{1+N^{2}} \text {. }
$$

This coefficient can be introduced in the following way. Let us assume that frequency $\omega$ of the oscillator depends on some governing parameter (normalized power of oscillations) $p \sim \tau_{f}^{2}$. Then the nonlinearity coefficient can be introduced as $N=d \omega / d p$. For the case of spintronic oscillators mentioned in [6], the oscillator frequency depends on the oscillation power $p$ as $\omega=\omega_{0}+N p$.

Now let us numerically calculate the nonlinear frequency shift $N=d \omega / d p$ for the case of an AFM oscillator.

The result of such calculations is shown in Fig. 3. As one can see, nonlinear frequency shift $N$ decreases monotonically with an increase in the applied DC current and, consequently, with an increase in the generation frequency. It should be noted that at the threshold point, when $\tau / \omega_{e}=0.5$, formally $N \rightarrow \infty$. This is an im- 


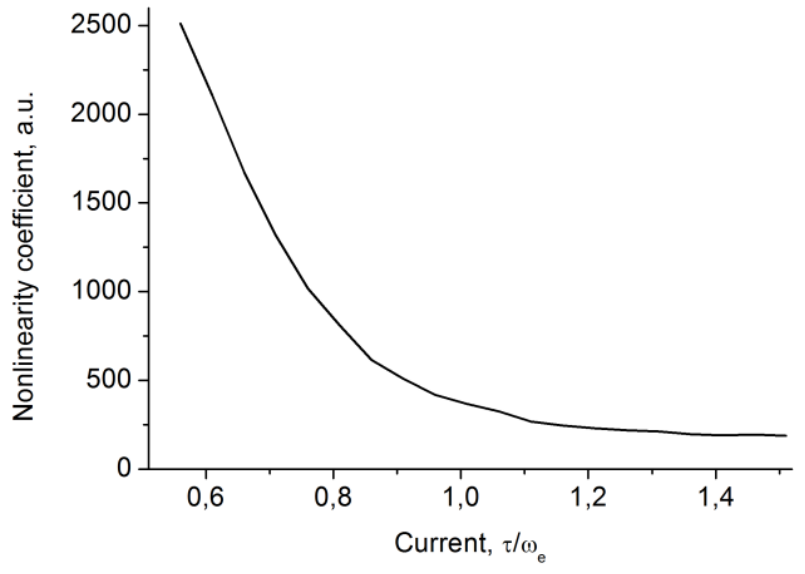

Fig. 3 - Dependence of the nonlinear frequency shift parameter $N$ on the normalized applied DC current $\tau / \omega_{e}$. Parameters of the system: $\alpha=0.01, H_{e x}=9 \cdot 10^{6} \mathrm{Oe}, H_{e}=625 \mathrm{Oe}$

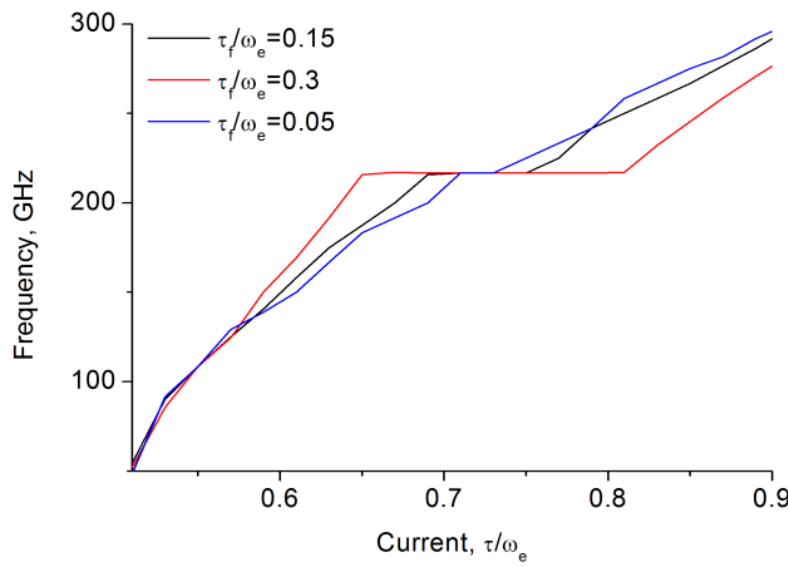

Fig. 4 - Dependence of the AFM oscillator frequency $\omega / 2 \pi$ on the normalized applied DC current $\tau / \omega_{e}$ for different normalized external signal amplitudes $\tau_{f} / \omega_{e}$. Calculation is performed using the system parameters: $\alpha=0.01, H_{e x}=9 \cdot 10^{6} \mathrm{Oe}, H_{e}=625 \mathrm{Oe}$

\section{REFERENCES}

1. I. Žutić, J. Fabian, S. Das Sarma, Rev. Mod. Phys. 76, 323 (2004).

2. S.I. Kiselev, J.C. Sankey, I.N. Krivorotov, N.C. Emley, R. J. Schoelkopf, R.A. Buhrman, D.C. Ralph, Nature 425, 380 (2003).

3. O.V. Prokopenko, Ukr. J. Phys. 60, 104 (2015).

4. V.E. Demidov, S. Urazhdin, H. Ulrichs, V. Tiberkevich, A. Slavin, D. Baither, G. Schmitz, S.O. Demokritov, Nat. Mater. 11, 1028 (2012).

5. J. Sinova, S.O. Valenzuela, J. Wunderlich, C.H. Back, T. Jungwirth, Rev. Mod. Phys. 87, 1213 (2015).

6. A.N. Slavin, V.S. Tiberkevich, IEEE Trans. Magn. 45, 1875 (2009).

7. O. Prokopenko, E. Bankowski, T. Meitzler, V. Tiberkevich, A. Slavin, IEEE Magn. Lett. 2, 3000104 (2011).

8. A.A. Tulapurkar, Y. Suzuki, A. Fukushima, H. Kubota, H. Maehara, K. Tsunekawa, D.D. Djayaprawira, N. Watanabe, S. Yuasa, Nature 438, 339 (2005).

9. O.V. Prokopenko, I.N. Krivorotov, T.J. Meitzler, E. Bankowski, V.S. Tiberkevich, A.N. Slavin, Spin-Torque Microwave Detectors, in: magnonics: From Fundamentals to Applications. Topics in Applied Physics (Vol. 125, Eds. S.O. Demokritov and A.N. Slavin), Berlin: Springer-Verlag, P. 143-161 (2013).

10. O.V. Prokopenko, A.N. Slavin, Low Temp. Phys. 41, 353 (2015).

11. B. Fang, M. Carpentieri, S. Louis, V. Tyberkevich, A. Slavin, portant result indicating that choosing an appropriate working point of the oscillator can lead to a substantial increase in its synchronization bandwidth.

Obviously, to achieve the maximum synchronization bandwidth, one should choose the oscillator working point near the generation threshold.

Now it is time to consider how an external signal amplitude $\tau_{f}$ influences the synchronization bandwidth. The corresponding dependences of the AFM oscillator frequency $\omega / 2 \pi$ on the normalized applied DC current $\tau / \omega_{e}$, when an external signal of various amplitudes $\tau_{f}$ is applied, are shown in Fig. 4. As one can see, the synchronization occurs around the frequency $\omega_{f}=2 \pi \cdot 200 \mathrm{GHz}$. A change in the external signal amplitude $\tau_{f}$ leads to a change of the synchronization bandwidth as it is predicted by (1).

\section{CONCLUSIONS}

In this work, we have theoretically and numerically investigated the synchronization of a Josephson-like AFM oscillator with an external terahertz-frequency signal. We found that due to large nonlinearity of the oscillator, its generation frequency nonlinearly depends on the applied DC current and the synchronization bandwidth depends not only on the external signal amplitude, but also on nonlinearity of the oscillator itself. The obtained results allow one to maximize the oscillator synchronization bandwidth by choosing an appropriate working point of the system above the generation threshold. The developed formalism and numerical simulations can also be used for the description of strongly nonlinear non-isochronous oscillators of any nature.

\section{ACKNOWLEDGEMENTS}

This work was supported in part by the grant No. 18BF052-01M of the Ministry of Education and Science of Ukraine, grant No. $1 \mathrm{~F}$ of the National Academy of Sciences of Ukraine and NATO SPS grant No. G5792.

N. Krivorotov, R. Tomasello, A. Giordano, H. Jiang, J. Cai, Y. Fan, Z. Zhan, B. Zhang, J.A. Katine, K.L. Wang, P.K. Amiri, G. Finocchio, Z. Zeng, Phys. Rev. Appl. 11, 014022 (2019).

12. V. Baltz, A. Manchon, M. Tsoi, T. Moriyama, T. Ono, Y. Tserkovnyak, Rev. Mod. Phys. 90, 015005 (2018).

13. R. Khymyn, I. Lisenkov, V. Tiberkevich, B.A Ivanov, A. Slavin, Sci. Rep. 7, 43705 (2017).

14. R. Khymyn, I. Lisenkov, J. Voorheis, O. Sulymenko, O. Prokopenko, V. Tiberkevich, J. Akerman, A. Slavin, Sci. Rep. 8, 15727 (2018).

15. O. Sulymenko, O. Prokopenko, I. Lisenkov, J. Åkerman, V. Tyberkevych, A. N. Slavin, R. Khymyn, J. Appl. Phys. 124, 152115 (2018).

16. O.R. Sulymenko, O.V. Prokopenko, V.S. Tiberkevich, A. N. Slavin, B. A. Ivanov, R. S. Khymyn, Phys. Rev. Appl. 8, 064007 (2017).

17. O.R. Sulymenko, O.V. Prokopenko, V.S. Tiberkevich, A.N. Slavin, IEEE Magn. Lett. 9, 3104605 (2018).

18. D.V. Slobodianiuk, O.R. Sulymenko, O.V. Prokopenko, IEEE 38th Int. Conf. on Electron. and Nanotechnology. (ELNANO, 24-26 April, 2018, Kiev, Ukraine) 470 (Kyiv: 2018).

19. E.G. Galkina, A.Yu. Galkin, B.A. Ivanov, Low Temp. Phys. 34, 522 (2008).

20. A. Pikovsky, M. Rosenblum, J. Kurts, Synchronization: a universal concept in nonlinear sciences (Cambridge University Press: 2003) 


\title{
Синхронізація антиферомагнітного джозефсонівського осцилятора зовнішнім сигналом
}

\author{
Д.В. Слободянюк, О.В. Прокопенко
}

Київський національний університет ілені Тараса Шевченка, вул. Володимирська, 64/13, 01601 Київ, Украӥна

Теоретично та числовими методами проаналізовано динаміку намагніченості в нелінійних антиферомагнітних спінтронних осциляторах під дією постійного та змінного зовнішніх сигналів. Показано можливість існування режиму синхронізації вказаних систем із зовнішнім змінним сигналом; проаналізовано особливості даного режиму синхронізації. Було показано, що ширина смуги синхронізації залежить не тільки від амплітуди зовнішньої сили (що е типовим), а й від нелінійності осцилятора. Така поведінка зумовлена великою нелінійністю системи. Шляхом проведення теоретичного та числового аналізу було встановлено, що частота генерації осцилятора залежить від зовнішнього керуючого сталого струму суттево нелінійним чином. Таким чином, правильний вибір робочої точки 3 певним значенням коефіціента нелінійності важливий для реалізації режиму синхронізації осцилятора і може бути використаний для максимізації смуги синхронізації. Отримані результати важливі для подальшої розробки антиферомагнітних терагерцових спінтронних осциляторів та їх практичного застосування. Розроблений формалізм та числові розрахунки також можуть бути використані для опису суттево нелінійних неізохронних осциляторів довільної природи.

Ключові слова: Антиферомагнетик, Осцилятор, Синхронізація, Нелінійність. 